\title{
Anterior Ischaemic Optic Neuropathy Differentiation of arteritic from non-arteritic type and its management
}

\author{
SOHAN SINGH HAYREH
}

Iowa City, Iowa, USA

\begin{abstract}
Summary
Anterior ischaemic optic neuropathy (AION), a common, visually crippling disorder, is discussed, with particular emphasis on differentiating AION due to giant cell arteritis (arteritic AION) from that not due to it (non-arteritic AION). Giant cell arteritis is an ophthalmic emergency because of imminent danger of bilateral total blindness, which is almost always preventable if the disease is quickly identified and treated urgently and aggressively. My studies have revealed that the best means of differentiating arteritic from non-arteritic AION is a combination of information from the following: systemic and visual symptoms of giant cell arteritis, high erythrocyte sedimentation rate and C-reactive protein, early massive visual loss, chalkywhite optic disc swelling, associated cilio-retinal artery occlusion, massive non-filling of the choroid on fluorescein fundus angiography and temporal artery biopsy. Management of giant cell arteritis and of arteritic AION is discussed. Current misconceptions about AION are pointed out.
\end{abstract}

Anterior ischaemic optic neuropathy (AION) is one of the most prevalent visually crippling diseases in the middle aged and elderly-a fact not fully recognised by ophthalmologists and neurologists.

The account of AION given in this paper is essentially based on my personal experience of the disease and not on a review of the extensive literature on the subject. I have studied the subject of AION clinically and experimentally over the past 20 years. For the past 15 years we have been prospectively investigating various aspects of $\mathrm{AION}$ in our Ocular Vascular Clinic at the University of
Iowa and have collected data on about 600 cases of AION.

\section{Pathogenesis of AION}

AION is due to acute ischaemia of the anterior part of the optic nerve, which consists of the optic nerve head and adjacent retrolaminar optic nerve. ${ }^{1-3}$ This part of the optic nerve is supplied mainly by the peripapillary choroid and by some direct branches from the short posterior ciliary arteries, with minor and differing contributions from other sources ${ }^{+-}$ (Fig. 1). Thus, posterior ciliary artery (PCA) circulation is the dominant source of blood

These studies have been supported by a rescarch grant from the National Institutes of Health (Grant No. EY-1151), and unrestricted grants from Research to Prevent Blindness, Inc, New York, and from the Alcon Research Institute

Correspondence to: Sohan Singh Hayreh, MD, PhD, DSc, FRCS, Department of Ophthalmology, University Hospitals and Clınics, Iowa City, Iowa 52242, USA. 


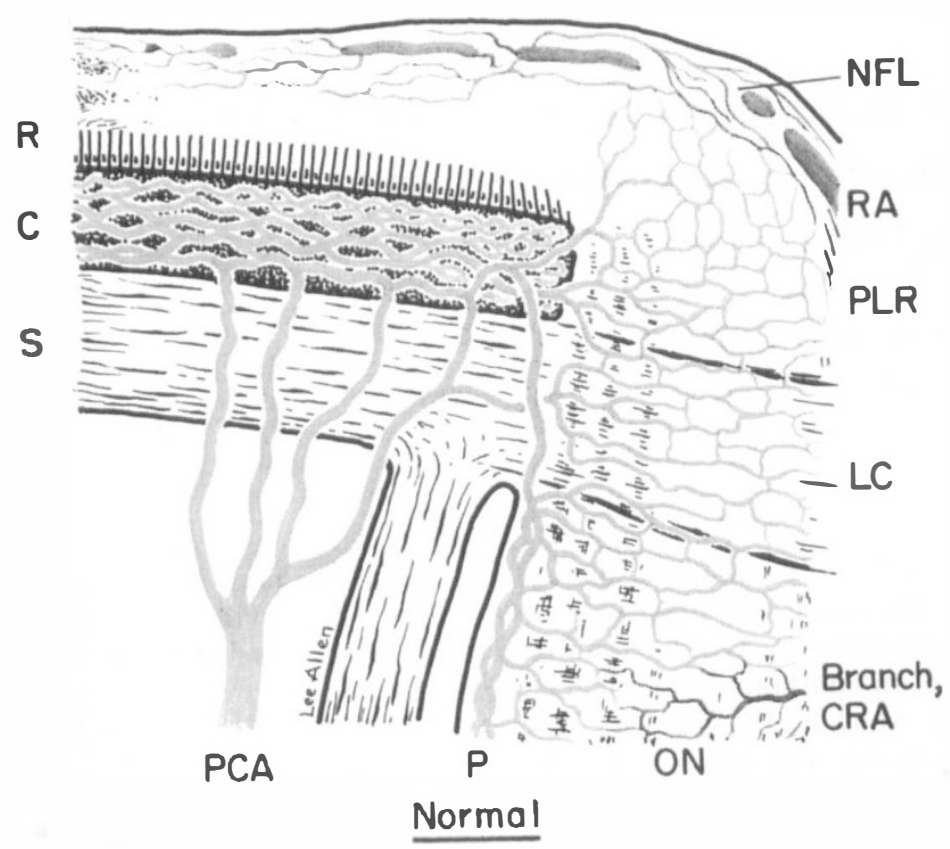

Fig. 1. Schematic representation of blood supply of the optic nerve head and retrolaminar optic nerve. $C=$ choroid, $C R A=$ central retinal artery, $L C=$ lamina cribrosa, $N F L=$ surface nerve fibre layer of the optic disc, $O N=$ optic nerve, $P=$ pia, $P C A=$ posterior ciliary artery, $P L R=$ prelaminar region, $R=$ retina, $R A=$ retinal arteriole, $S=$ sclera. (Reproduced from Hayreh ${ }^{5}$ ).

supply to this region. Usually there are two or three PCAs arising from the ophthalmic artery, arranged medial and lateral to the optic nerve and designated as medial PCA and lateral PCA respectively. ${ }^{9,10}$ The PCAs in vivo physiologically behave as end-arteries ${ }^{10,11}$ and the watershed zone between the PCAs may be situated anywhere between the fovea and the nasal border of the optic disc $;{ }^{6-8,10}$ the location of the watershed zone plays an important role in determining the site and extent of optic nerve head ischaemia. ${ }^{6-8}$ The blood supply of the anterior part of the optic nerve shows a marked inter-individual variation, ${ }^{6-8}$ which explains variation in the pattern of visual loss associated with AION in different eyes.

In many patients no definite cause can be discovered for the development of AION; however, the known causes of AION include giant cell arteritis (temporal or cranial arteritis) ${ }^{3}$, diabetes mellitus, ${ }^{12}$ arteriosclerosis, atherosclerosis, arterial hypertension, malignant arterial hypertension, ${ }^{13}$ arterial hypo- tension, collagen vascular diseases, massive/ recurrent systemic haemorrhages, ${ }^{14}$ valvular heart disease, carotid artery disease, migraine, marked chronic optic disc oedema of any cause $\mathrm{e}^{15}$ and raised intraocular pressure, ${ }^{16}$ with giant cell arteritis and diabetes mellitus as the most important causes.

From the aetiology and pathogenesis point of view, AION can usually be subdivided into two types: (i) due to thrombotic or embolic lesions of the PCAs or their subdivisions, and (ii) due to temporary hypoperfusion or nonperfusion of the nutrient vessels in the anterior part of the optic nerve, usually as a result of fall in the perfusion pressure in the peripapillary choroid; the second type of AION is by far the commonest variety. We have discussed the pathogenesis of AION, in general $^{2,3,17,18}$ and in specific conditions, ${ }^{12-16,19,20}$ in detail elsewhere.

\section{Clinical classification of AION}

Based on the aetiology of AION, and from 
the clinical management point of view, AION can also be classified as arteritic (caused by giant cell arteritis), and non-arteritic (from other causes) - the latter includes those cases where there is no apparent cause.

\section{Clinical features of $A I O N$}

AION usually presents with classical symptoms and signs, so that it is one of the easiest diagnoses to make in ophthalmology.,17,21 There is sudden, painless visual deterioration in one eye, usually discovered on waking in the morning. On examination, the visual acuity may vary from better than $6 / 6$ to no light perception (Table). ${ }^{22}$ Perimetry usually reveals relative or absolute inferior altitudinal defect, inferior nasal sectoral defect or central scotoma, and less commonly other optic disc related field defects (Fig. 2). ${ }^{22}$ Fundus examination initially shows optic disc oedema, usually with splinter retinal haemorrhage(s) at the discmargin (Figs. 3, 4a, 5a, 6a, 7) .,17,2. $^{2}$ The disc oedema usually resolves spontaneously in about two months and is replaced by sectoral or more often generalised optic atrophy. The fellow, normal optic disc shows either no cup or only a very small cup. ${ }^{20}$ Fluorescein angiography during the initial phase usually shows filling defects in the optic disc, peripapillary choroid and choroidal watershed zones (Figs. 4b, 5b), and in giant cell arteritis much more extensive choroidal filling defects (Figs. 6b, c)..$^{3,6,17,21,23}$ AION usually starts as a unilateral condition but after days, months or years may become bilateral-the estimated 25th-percentile time to development of bilateral AION in our series was 0.4 months for untreated arteritic AION and 32.4 months for non-arteritic AION. ${ }^{19}$

Table Visual acuity in arteritic and non-arteritic AION (from Hayreh \& Podhajsky ${ }^{22}$ )

\begin{tabular}{lcc}
\hline & $\begin{array}{c}\text { Arteritic } \\
\text { AION } \\
\text { (per cent) }\end{array}$ & $\begin{array}{c}\text { Non-arteritic } \\
\text { AION } \\
\text { (per cent) }\end{array}$ \\
\hline $\begin{array}{l}\text { Normal to fairly good visual acuity: } \\
\text { 6/6 or better }\end{array}$ & 14 & 26 \\
6/12 or better & 26 & 41 \\
6/30 or better & 40 & 63 \\
Poor visual acuity to blind: & & \\
Count fingers & 14 & 17 \\
Hand motion & 11 & 5 \\
Light perception & 6 & 1.5 \\
No light perception & 29 & 2 \\
\hline
\end{tabular}

\section{Management of AION}

Once a patient in the late fifties or older is diagnosed to have AION, the first, most important step is to rule out giant cell arteritis because of imminent danger of bilateral total blindness which is almost entirely preventable if the disease is quickly identified and treated urgently and aggressively. In fact, Jennings, ${ }^{24}$ more than half a century ago, stressed that giant cell arteritis 'ranks as the prime medical emergency in ophthalmology. There being no other disease in which the prevention of blindness depends so much on prompt recognition and early treatment.'

With this abbreviated introduction on AION, I wish to deal briefly with the following three aspects of AION:

\section{(A) Differentiation of arteritic from non-arter- itic AION}
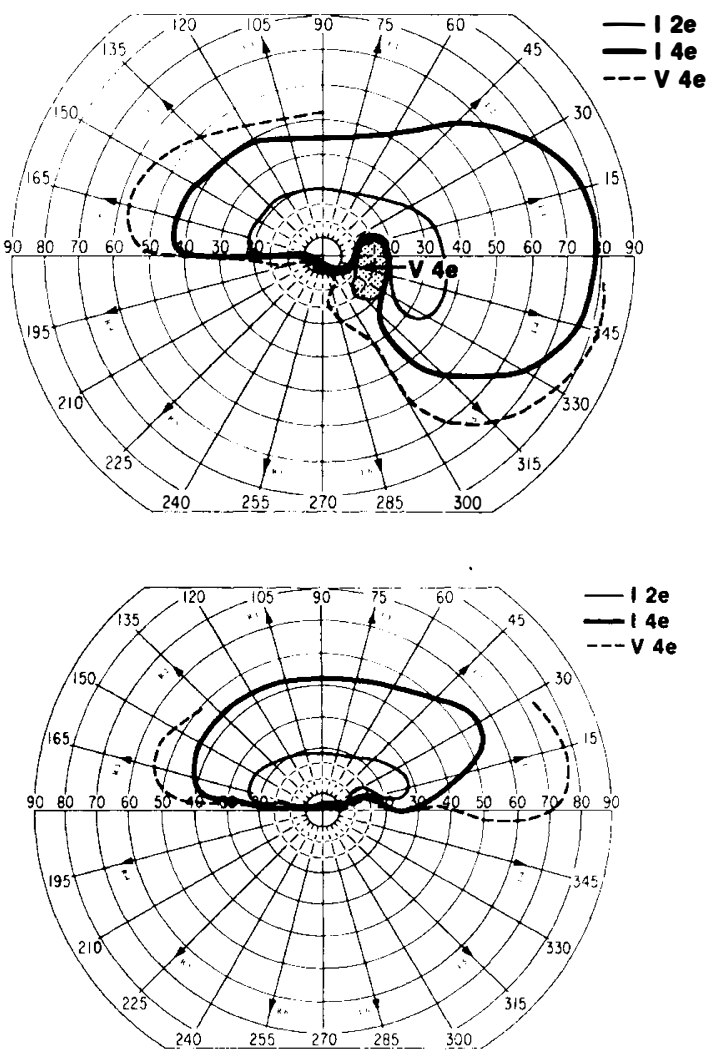

Fig. 2. Visual field defects in AION with Goldmann perimeter: (a) showing inferior nasal quadrantic defect with $I_{4 e}$ (heavy line) and $V_{4 e}$ (broken line), and inferior altitudinal defect with $I_{2 e}$ (thin line); (b) showing inferior altitudinal defect with all the 3 isopters. 


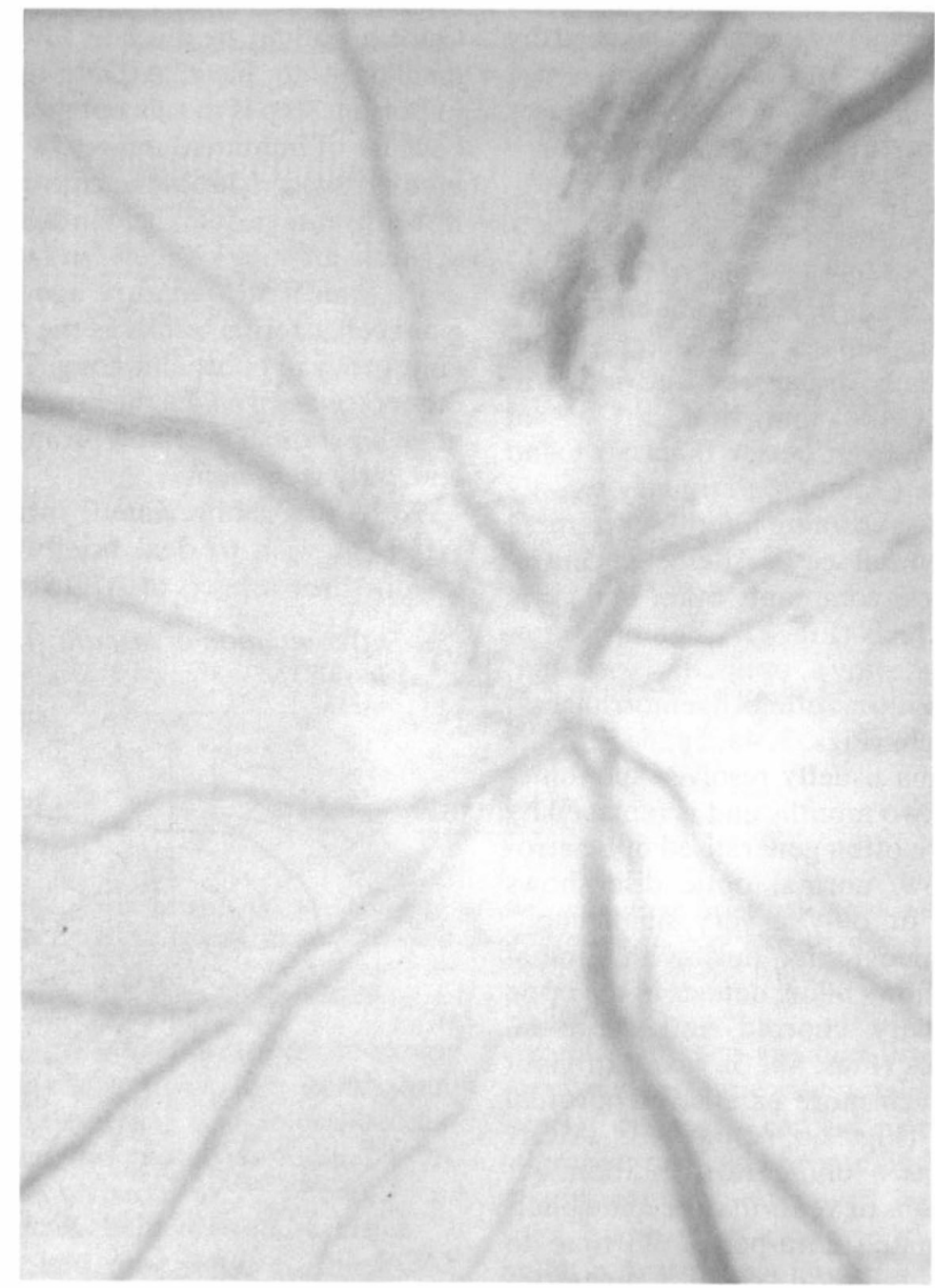

Fig. 3. Fundus photographs of right eye with non-arteritic AION showing optıc disc oedema and flame-shaped haemorrhages during the acute phase.

(B) Management of arteritic AION and giant cell arteritis

(C) Currently prevalent misconceptions about AION

\section{(A) Differentiation of Arteritic From Non- Arteritic AION}

Since giant cell arteritis is an ocular emergency, it is imperative to differentiate arteritic from non-arteritic AION at the earliest possible moment, to enable us to start corticosteroid therapy immediately in order to prevent any further loss of vision. The criteria for such a differentiation discussed here are mainly drawn from the studies conducted in our clinic. In addition to the 600 patients of AION (about 75 arteritic and 525 non-arteritic) studied in our clinic prospectively and in detail, we have also followed prospectively about 30 cases of giant cell arteritis without any AION or any other visual complaint. This clinical material, combined with my experience over the past two decades, has revealed that the following criteria collectively provide information which can help to differentiate 


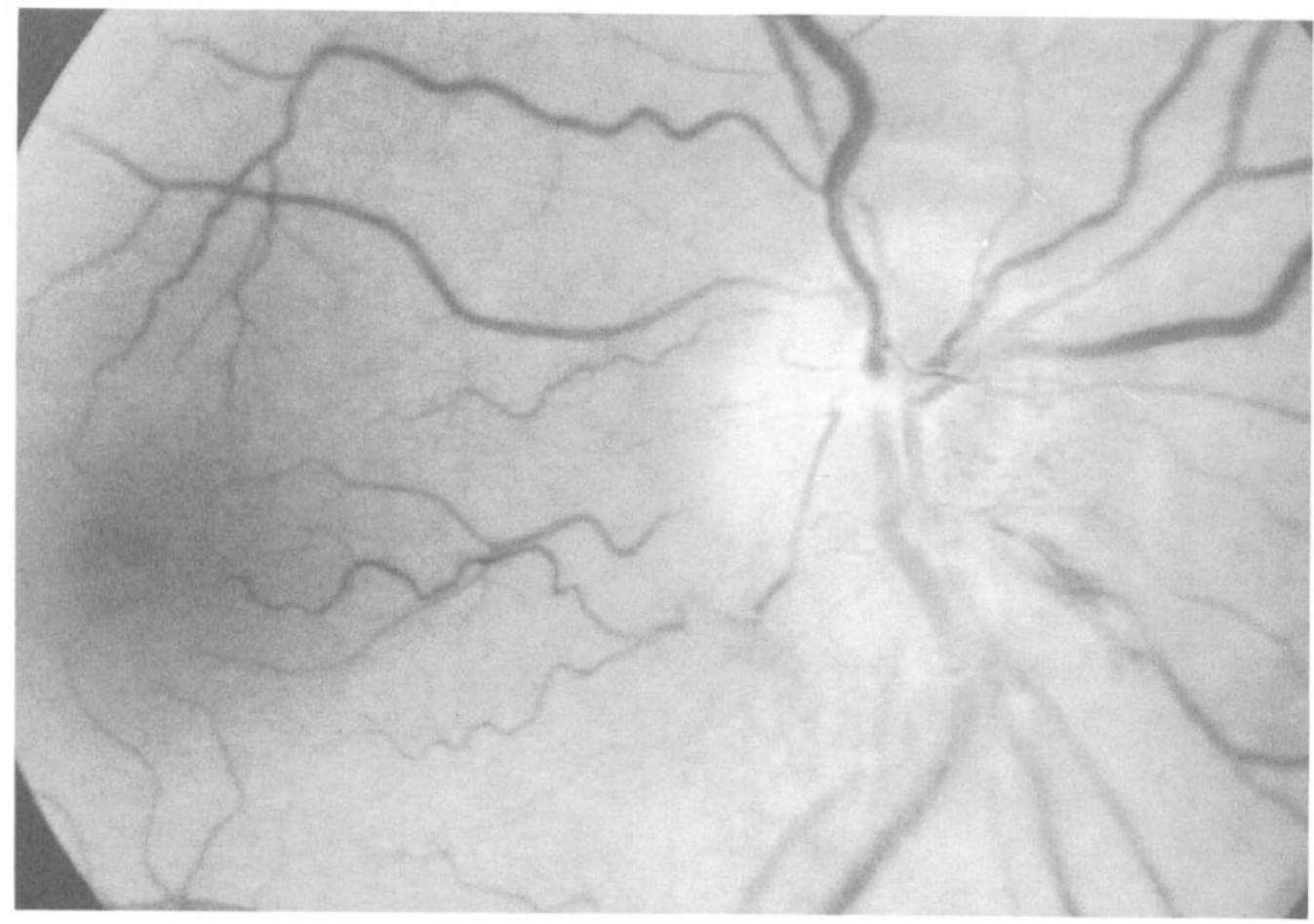

Fig. 4. Right eye with non-arteritic AION (a) fundus photograph showing optic disc oedema and a splinter haemorrhage, and (b) fluorescein fundus angiogram showing non-filling of temporal parts of the peripapillary choroid and optic disc and of upper half of the choroidal watershed zone. (Fig. $4 b$ reproduced from Hayreh ${ }^{6}$ ).

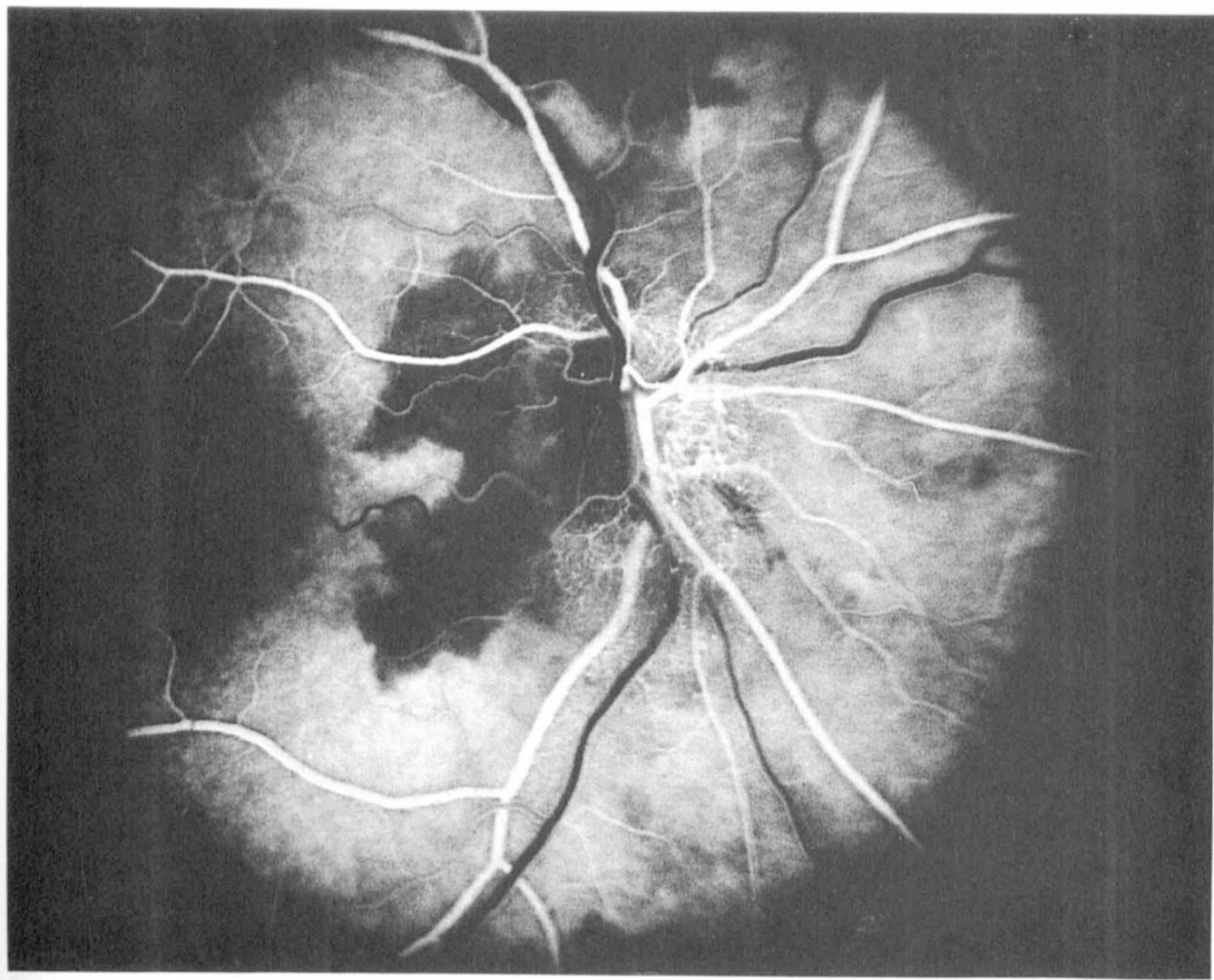

Fig. 4 b. 


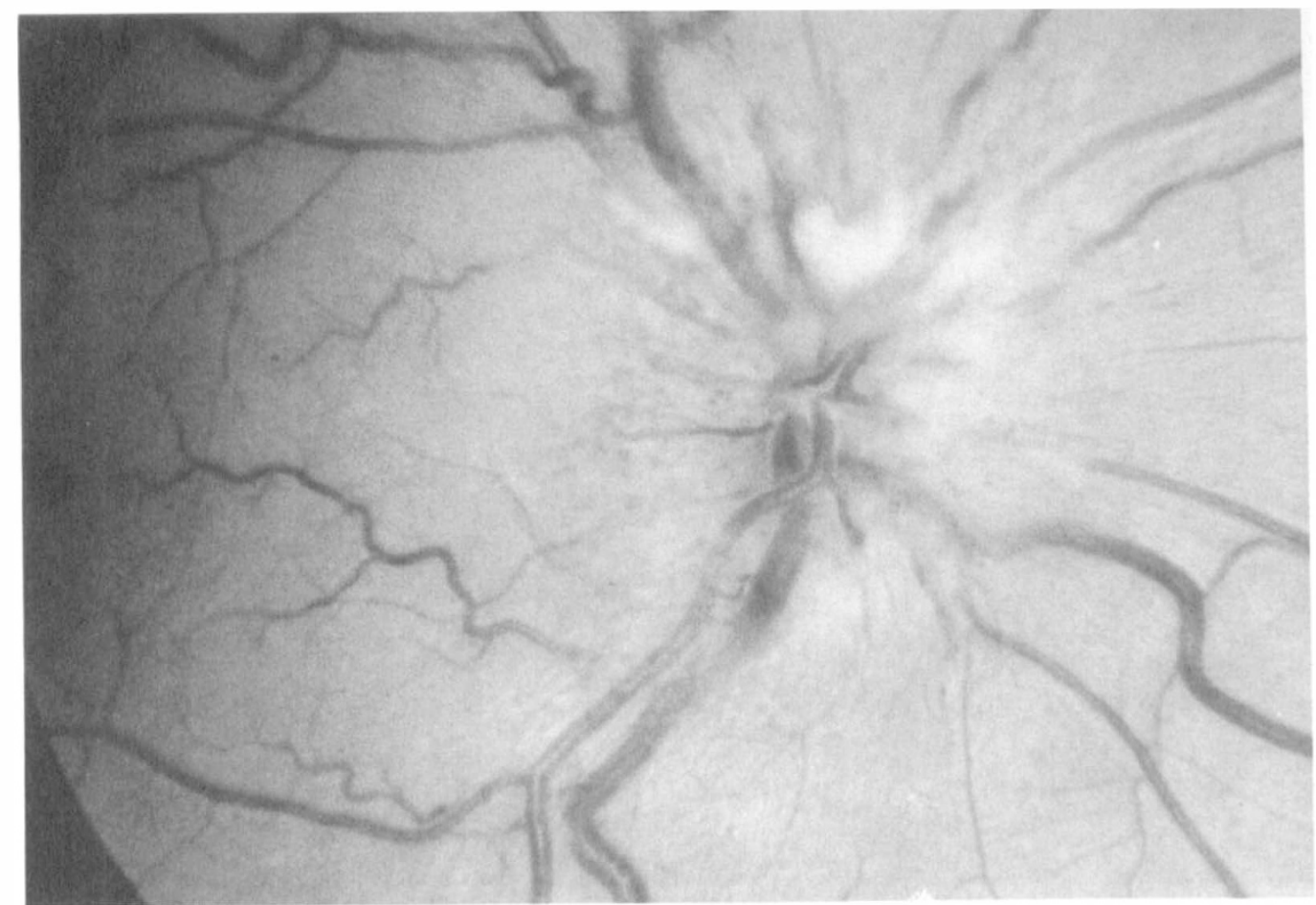

Fig. 5. Right eye with non-arteritic AION (a) fundus photograph showing optic disc oedema and fine splinter haemorrhages, and (b) fluorescein fundus angiogram showing non-filling of the choroidal watershed zone between the lateral and medial PCAs and of the temporal part of optic disc. (Fig. $5 b$ reproduced from Hayreh ${ }^{6}$ ).

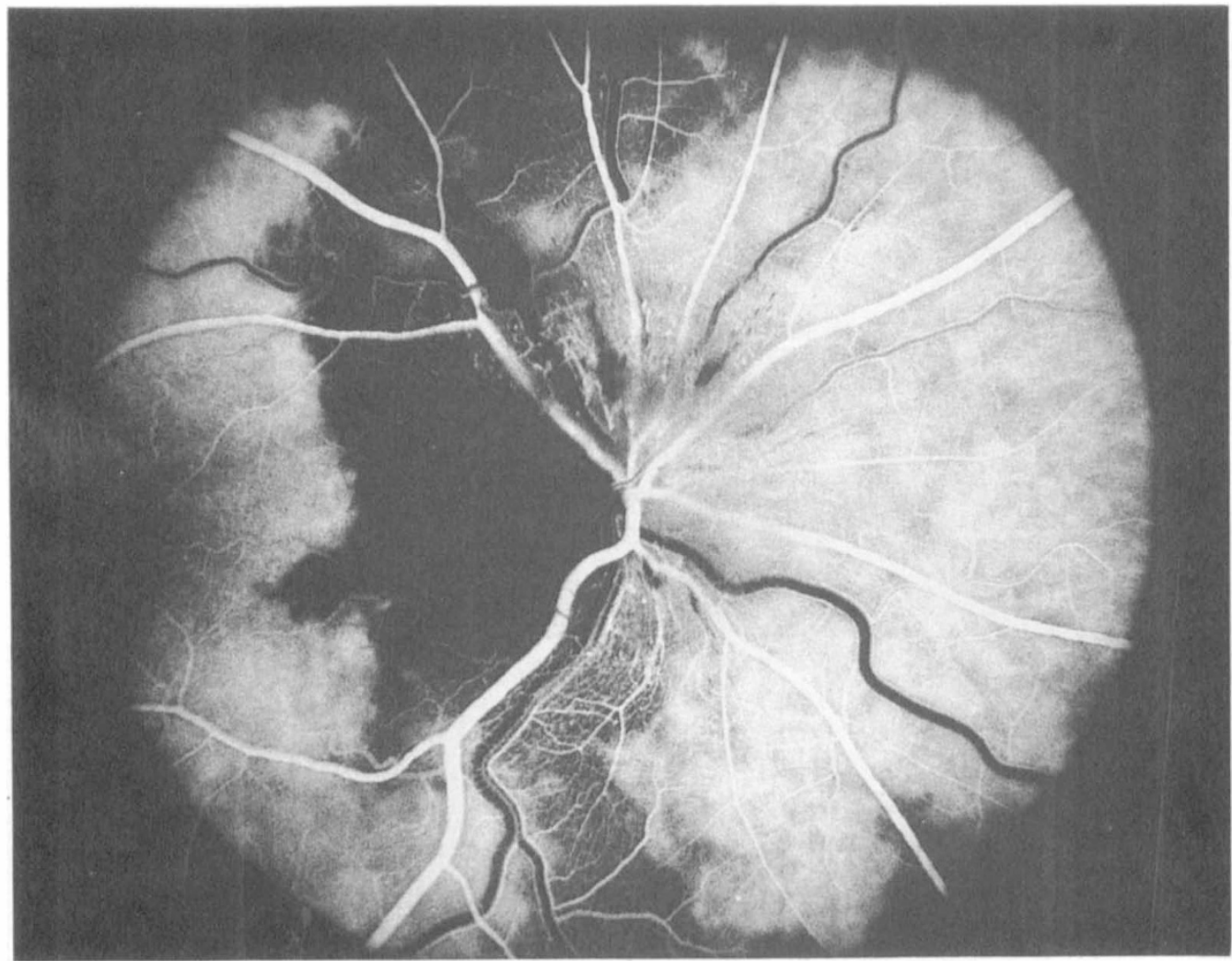

Fig. 5b. 


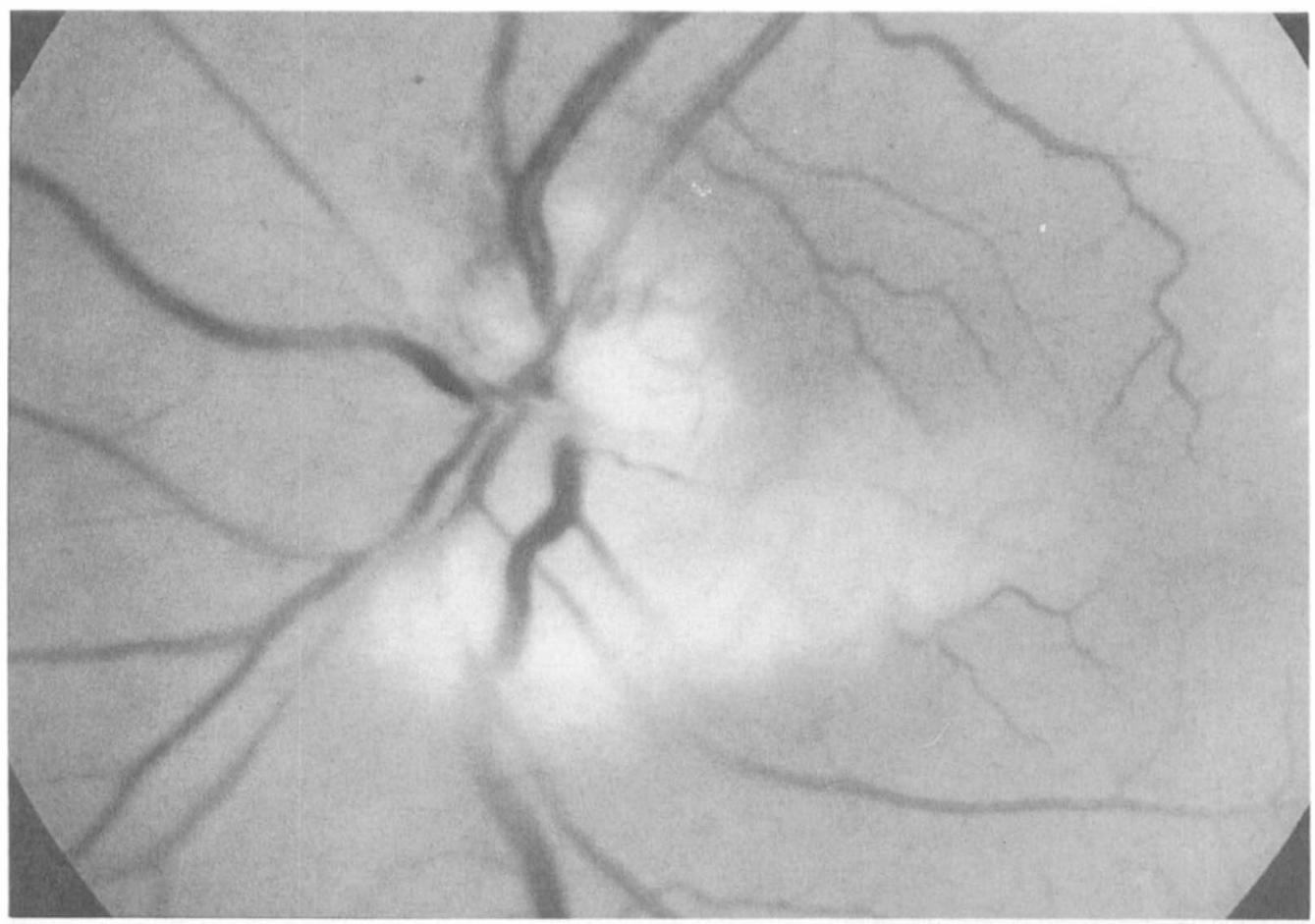

Fig. 6. Left eye with arteritic AION and associated cilio-retinal artery occlusion (a) fundus photograph showing chalky-white optic disc oedema and a patch of retinal infarction in the distribution of cilio-retinal artery; (b-d) fluorescein fundus angiograms showing normal filling of the central retinal artery and of the choroid supplied by the lateral PCA, but no filling of the choroid and optic disc supplied by the medial PCA and of the cilio-retinal artery (in $b$ and $c)$, and late staining of the disc (d). (Fig. 6c reproduced from Hayreh ${ }^{17}$ ).

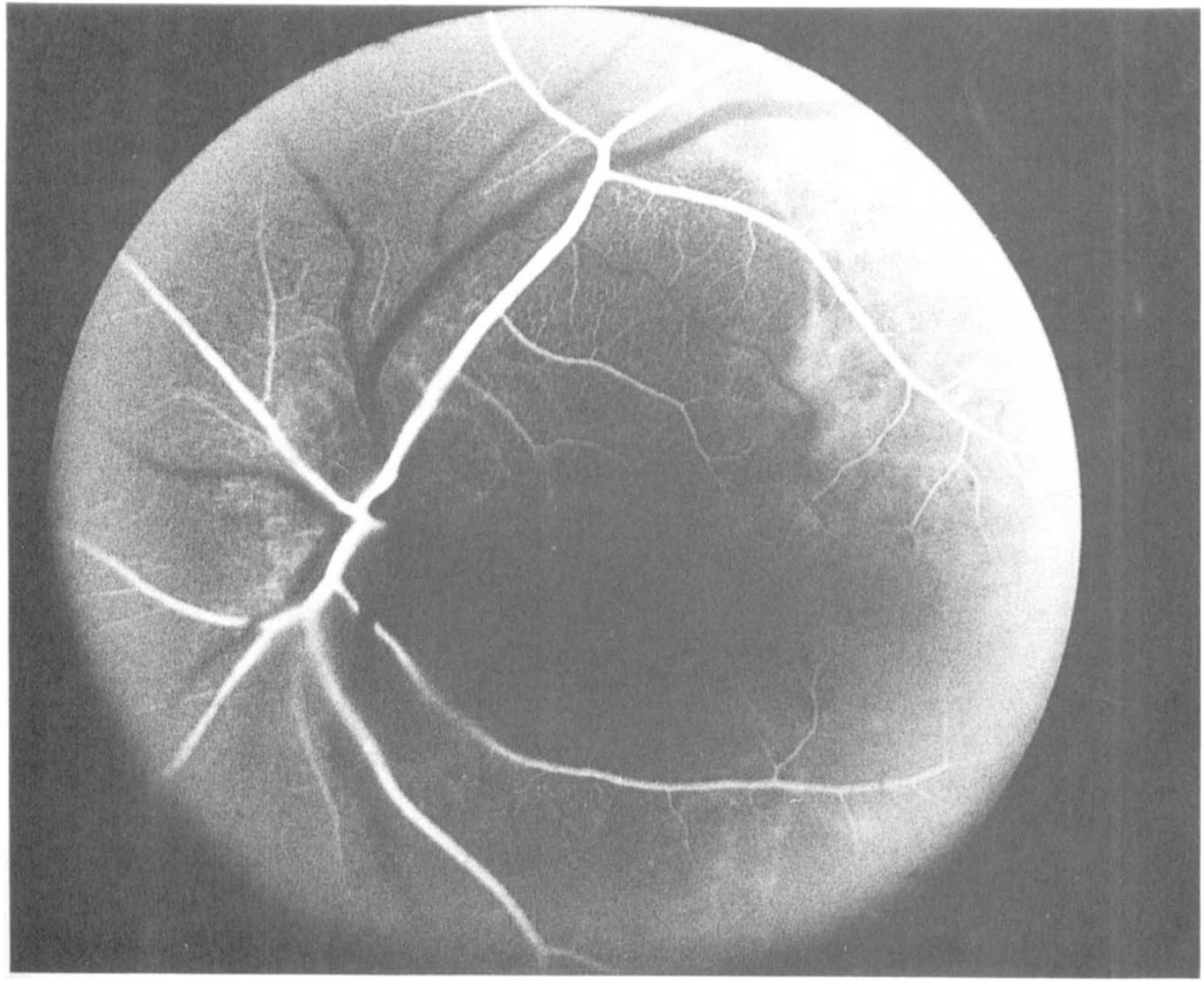

Fig. $6 b$. 


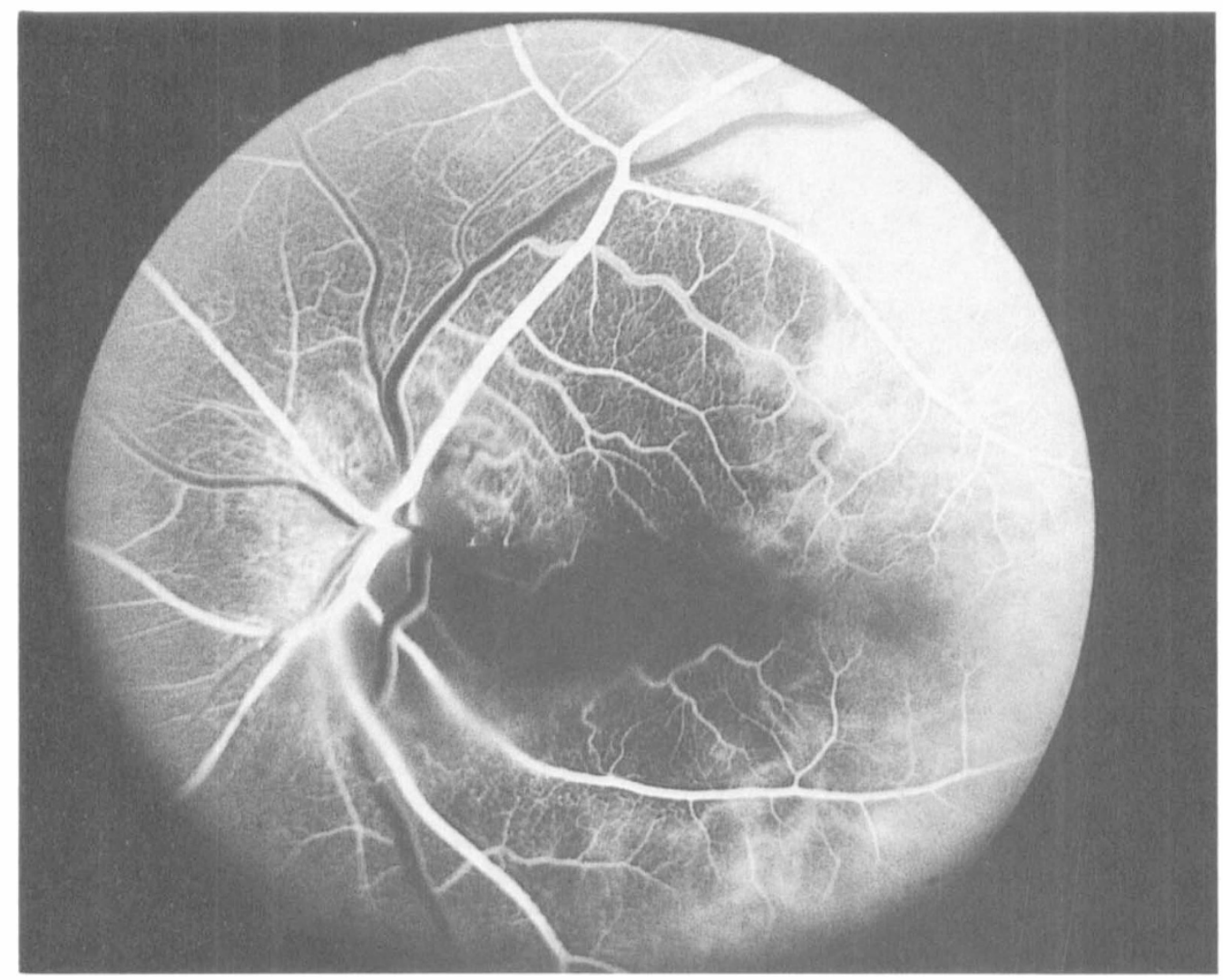

Fig. 6c.

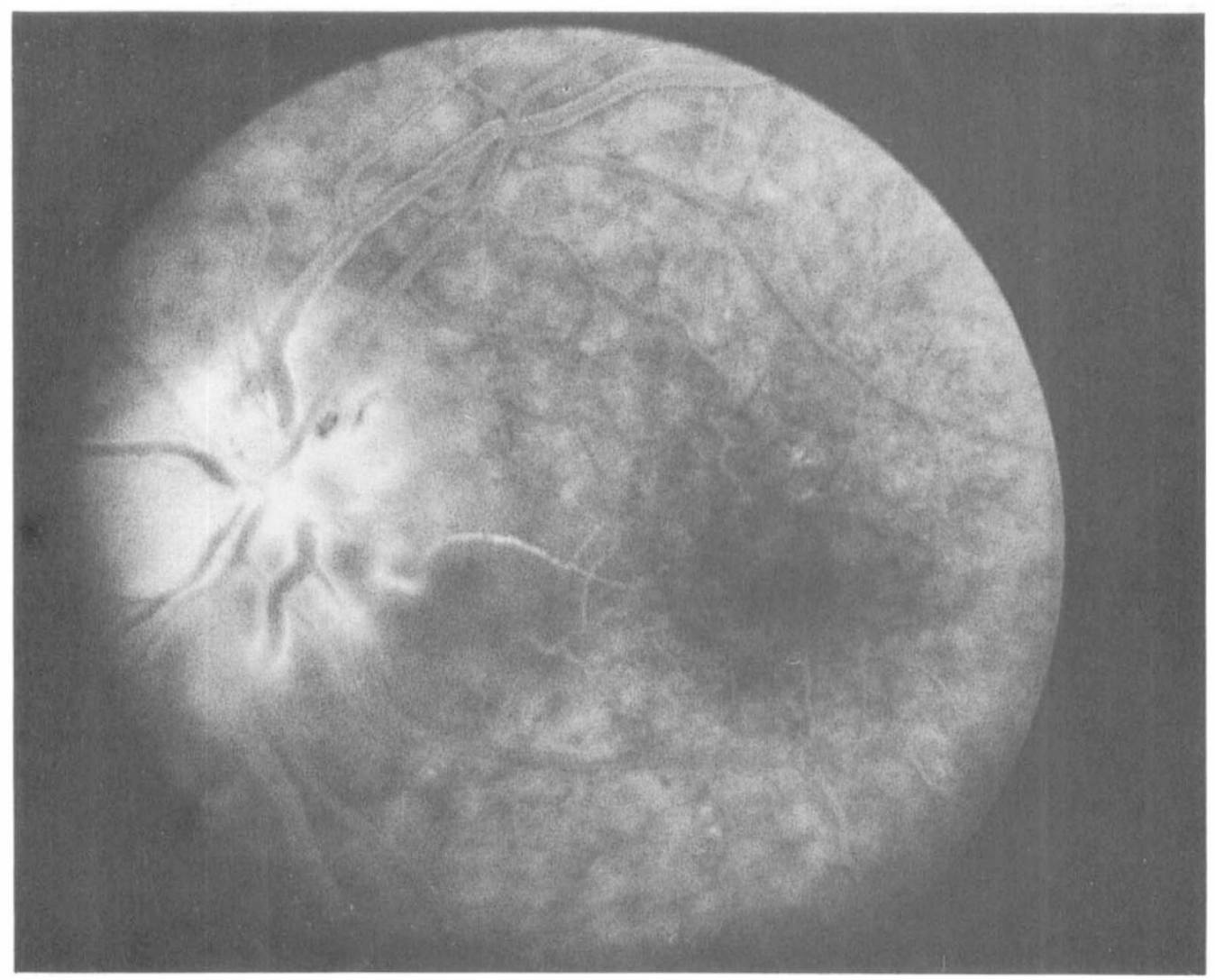

Fig. 6d. 


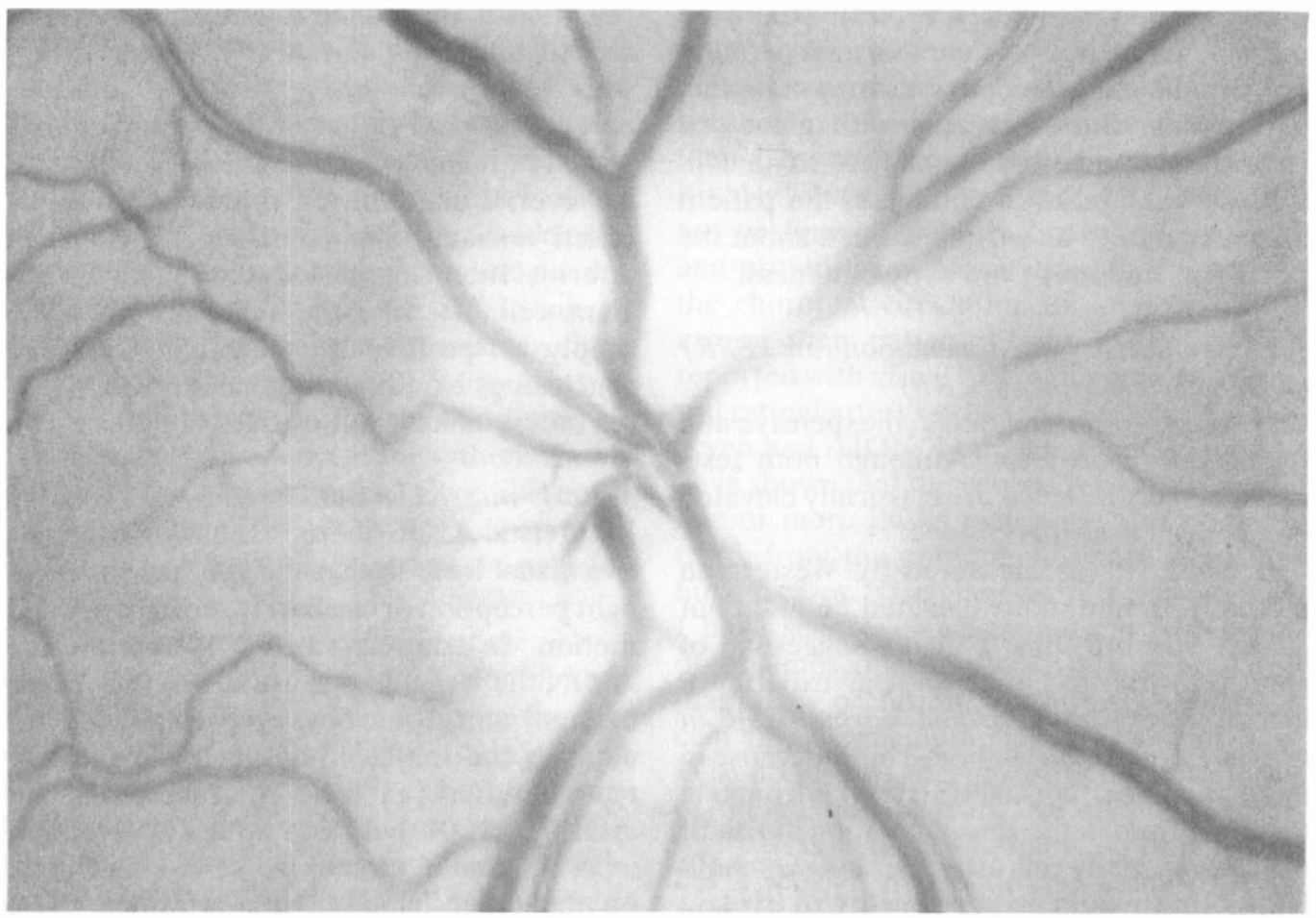

Fig. 7. Fundus photograph of right eye with arteritic AION, showing chalky-white swelling of the optic disc.

arteritic from non-arteritic AION almost invariably.

\section{Systemic symptoms of giant cell arteritis}

Typically the patient is sixty or older, more often female than male, and complains of vague aches and pains, malaise, anorexia, 'flu'-like symptoms, weight loss, fever of unknown origin, headaches, scalp tenderness, neck pain, jaw claudication, anaemia or other vague systemic symptoms; the patient feels tired, sleepy and generally unwell. Paulley and Hughes ${ }^{25}$ admirably summarised the symptoms when they stated that 'When elderly people begin to fail mentally and physically, this disorder should be one of the first to be considered'. We have seen many patients who have been subjected to extensive, highly expensive and totally unnecessary systemic investigations to rule out malignancies and other systemic causes for their symptoms and the missed diagnosis ultimately resulted in blindness. I find widespread lack of awareness among physicians of this important, typical symptom-complex of giant cell arteritis. It is not at all uncommon in our experience to find patients who have repeatedly given a classical history of this disease to their physicians and yet the diagnosis was totally missed and the patient went blind in one or both eyes. However, not all patients with giant cell arteritis have systemic symptoms; in occult giant cell arteritis, the patient is perfectly fit and healthy and yet has classical evidence of giant cell arteritis. Tender, hard, nodular, prominent and non-pulsatile temporal arteries are described as a classical finding in these patients; however, perfectly normal and pulsatile temporal arteries are not uncommon in typical giant cell arteritis. These are some of the pitfalls, and it is important to be aware of them.

\section{Visual symptoms of giant cell arteritis}

Amaurosis fugax is an important symptom of giant cell arteritis, because it is rarely noticed in non-arteritic AION. The presence of amaurosis fugax is an ominous sign of impending AION in patients with giant cell arteritis, and these eyes are at risk of develop- 
ing blindness very quickly. Typically, there is a sudden, painless, spontaneous and permanent visual loss. A few patients may complain of diplopia. Some patients with giant cell arteritis are somewhat euphoric, so that in spite of bilateral total blindness, the patient may seem not to be very concerned about the visual loss and may even deny blindness.

\section{High erythrocyte sedimentation rate (ESR) and $C$-reactive protein (CRP)}

These are two simple, quick, inexpensive and readily available tests. Although both tests are non-specific, levels are classically elevated in giant cell arteritis.

If the ESR (as measured by Westergren method) is markedly elevated, e.g. about $80 \mathrm{~mm}$ or more, this is highly suggestive of giant cell arteritis; however, our experience has shown that the so-called 'normal ESR' in no way rules out this disease. This is because in our experience, 'normal ESR' varies from one to over $40 \mathrm{~mm}$ in the age-population at risk of developing giant cell arteritis, and we could find no haematologic abnormality to explain such a wide variation. I have seen AION with active giant cell arteritis (confirmed on temporal artery biopsy) where the ESR was $5 \mathrm{~mm}$ with the Westergren method. It is very important to bear in mind that there is a tremendous variation in the normal levels of ESR in the elderly and this has not been adequately stressed in the literature, resulting in missing giant cell arteritis; ESR in the teens, twenties or even thirties has often been dismissed as 'normal'. This serious pitfall regarding ESR should be kept in mind.

For the past few years, in addition to ESR, we have used CRP to evaluate and manage these patients. A rise in CRP level in serum and other body fluids is produced by inflammatory processes in the body. ${ }^{26}$ Usually changes in CRP correlate with the ESR; however, in some aspects it behaves differently from ESR. CRP does not rise during some viral diseases, some severe toxic states, and in some forms of chronic inflammatory arthritis, ${ }^{27}$ when ESR does rise. Also, we have found much less fluctuation in CRP than in ESR. In our experience, combined information from CRP and ESR is very useful in diagnosis and evaluation of patients with giant cell arteritis and in their follow-up on systemic corticosteroids. A normal CRP level ( $\leqslant 1 \mathrm{mg}$ ) with equivocal ESR strongly indicates absence of giant cell arteritis or good control with treatment, even when ESR is elevated; however, a markedly elevated CRP with socalled 'normal ESR' would suggest giant cell arteritis. In some previous studies ${ }^{28}$ on CRP in giant cell arteritis, the results were given simply as 'positive' or 'negative' CRP and conclusions based on those could be misleading unless exact levels of CRP are given.

\section{Early massive visual loss}

In arteritic AION there is usually early massive visual loss, so that the eye has either no light perception or can barely see light or hand motion. In contrast to that in non-arteritic AION the visual loss is usually not so severe to begin with. Some time ago we analysed our data on the initial visual acuity in the two types of AION (Table). ${ }^{22}$ This revealed that in arteritic AION there was no light perception in $29 \%$, hand motion or worse vision in $46 \%$; on the other hand, in non-arteritic AION hand motion or worse vision was in only $9 \%$. Thus, early massive visual loss is highly suggestive of arteritic AION but normal visual acuity does not rule this out (Table).

\section{Chalky-white optic disc swelling}

If the optic disc swelling is chalky-white initially (Fig. 7), it is extremely suggestive of arteritic AION because this is exceedingly rare in non-arteritic AION. ${ }^{3,23}$ However, about $50 \%$ of eyes with arteritic AION do not show this and ophthalmoscopic disc appearance is similar to that of non-arteritic AION (Fig. 3, 4a, 5a).

\section{AION associated with cilio-retinal artery occlusion}

In our experience, when optic disc oedema of AION is initially associated with cilio-retinal artery occlusion (Fig. 6), it is almost always diagnostic of arteritic AION; I have yet to see this in a non-arteritic AION ${ }^{3,23}$ In giant cell arteritis the primary lesion responsible for AION is thrombotic occlusion of the PCA. If a PCA is occluded, it infarcts not only the area of the anterior optic nerve supplied by it (Fig. 1) but also cuts out blood flow in the 
corresponding cilio-retinal artery. In contrast to that, our fluorescein fundus angiographic studies have consistently shown that nonarteritic AION is almost always due to transient non-perfusion or hypoperfusion of the nutrient vessels in the anterior part of the optic nerve because of a fall in perfusion pressure in the peripapillary choroid, and not due to PCA occlusion ${ }^{6,17,21}$ (Fig. 4b, 5b). In spite of my repeatedly stressing the latter fact over the years, I am constantly being misquoted by various authors as stating that non-arteritic AION is due to PCA occlusion-this is simply not so in the vast majority of cases. That is why in non-arteritic AION there is no associated occlusion of the cilio-retinal artery.

\section{Massive choroidal non-filling of the choroid on fluorescein fundus angiography} If angiography is performed during the first days after the onset of arteritic AION, it almost always shows massive choroidal nonfilling, corresponding to the occluded PCA (Fig. 6b, c). ${ }^{3,6,17,21,23}$ This is almost always diagnostic of arteritic AION. In our experience the medial PCA is involved much more frequently than the lateral PCA by giant cell arteritis (Fig. 6b, c). The area supplied by the medial PCA shows a marked inter-individual variation, so that it may supply the entire nasal choroid up to the foveal region, including the entire optic nerve head (Fig. 6b, c), or it may stop short nasal to the medial peripapillary choroid so that the optic nerve head is supplied entirely by the lateral PCA; or any variation between the two extremes. ${ }^{6-8}$ With the passage of time after the onset of arteritic AION, we have found that collateral circulation in the choroid progressively results in filling of the involved choroid so that fluorescein angiography performed a week or more after the onset may not show any such massive filling defect. In non-arteritic AION, however, such massive choroidal non-filling is extremely rare. ${ }^{6}$

Recently, Bosley et al..$^{29}$ described the role of ocular pneumoplethysmography in the diagnosis of giant cell arteritis. They studied nine patients with giant cell arteritis (with abnormal temporal artery biopsy) and visual loss (uniocular in seven and binocular in two). They stated that in giant cell arteritis ocular pulse amplitude and calculated ocular blood flow were reduced as compared to the normals and non-arteritic AION. This is not surprising; this is just another way to evaluate the PCA occlusion caused by giant cell arteritis. However, unfortunately the authors did not perform fluorescein fundus angiography and provided no information on the state of the choroidal circulation on angiography in any of their patients. Four of the 11 eyes reported with visual loss in this series had central retinal artery occlusion and the remaining seven had AION. In my anatomical studies I have shown that the central retinal artery and one or more PCAs may arise by a common trunk from the ophthalmic artery in $60 \%$ of human cases. ${ }^{9,30}$ In giant cell arteritis patients, I have seen eyes which present with what, ophthalmoscopically, looks like central retinal artery occlusion, but in fact, on fluorescein fundus angiography, turns out to have PCA occlusion too, because of the thrombosis of their common trunk by giant cell arteritis. ${ }^{3,23}$ It is well known that giant cell arteritis has a special predilection to involve PCAs. Bosley et al. ${ }^{29}$ reported that ocular pulse amplitude improved with the passage of time and (erroneously) attributed this to corticosteroid therapy; our fluorescein angiographic studies, in patients with arteritic AION and in rhesus monkey eyes after experimental PCA occlusion, have consistently shown that the choroidal vascular bed in the involved area starts to fill progressively with the passage of time because of establishment of collateral circulation $^{11}$ which has nothing to do with corticosteroid therapy. Since ocular pneumoplethysmography essentially evaluates the choroidal circulation, other conditions causing choroidal insufficiency would give false positive results; the authors reported eight false positive results in non-arteritic AION. I find that fluorescein fundus angiography, a safe, routine and readily available test, usually gives much better and more detailed information on the PCA, choroidal and optic disc circulations in giant cell arteritis than ocular pneumoplethysmography is likely to do. Moreover, there are some contraindications to doing ocular pneumoplethysmography in persons of this age group.

\section{Temporal artery biopsy}

This must be performed in every patient having 
a high index suspicion of giant cell arteritis or of arteritic $A I O N$, to confirm and establish the diagnosis even though all other parameters may be classical of the disease. This morphological documentation of giant cell arteritis is essential to justify committing a patient to protracted systemic steroid therapy, in view of the possible serious complications of such a long-term treatment and to safeguard against possible litigation emerging from such complications. Temporal artery biopsy should be performed as soon as possible, but there is absolutely no justification to withhold systemic corticosteroid therapy until biopsy is done, because giving such treatment before the biopsy does not alter the outcome of the biopsy.

Since Birkhead et al. ${ }^{31}$ in 1957 pointed out that involvement of the temporal artery by giant cell arteritis may be focal and segmental, the topic of 'skip lesions' in temporal artery in this disease has been raised from time to time. Cohen and Smith ${ }^{32}$ did not find any example of 'skip lesions' in their study of temporal artery biopsies from 42 patients. A number of studies, however, have shown the presence of 'skip areas ${ }^{33,34}$ strongly indicating that such areas do exist. This is obviously of great clinical importance because examination of a 'skip area' alone, showing no granulomatous lesions, would give a false negative result and cause the physician to miss the diagnosis of giant cell arteritis. To minimise the risk of a false negative temporal artery biopsy and to diminish the chance of erroneous information from a 'skip area', our routine is to remove a long piece of the temporal artery and our pathologist serially sections it. He has discovered skip areas located both circumferentially and longitudinally but serial sectioning of a long segment of the artery removed at biopsy reduces markedly the danger of a false negative biopsy. Studies by Wells et al. ${ }^{35}$ from our Department have shown that direct immunofluorescence microscopy of temporal artery biopsy sections is not more sensitive or specific than light microscopy, thus they questioned its routine use as a diagnostic test. In a rare case, however, they found immunofluorescence microscopy identified temporal arteritis despite negative findings by light microscopy. In patients with a strong clinical suspicion for giant cell arteritis we biopsy the second side if one side shows no granulomatous lesion. Blodi ${ }^{36}$ found no case of false negative biopsy in his series. Hedges et al. ${ }^{37}$ found it in $5 \%$ of their cases, and Hall et al..$^{38}$ in $6 \%$. In my experience in our clinic, I saw four such patients during the early stages of our study who met all the remaining criteria for arteritic AION mentioned above, and whose therapeutic response and follow-up course was exactly like giant cell arteritis, but who had a negative biopsy on both sides; at that time we were not very particular about removing a large piece of the temporal artery and doing serial sectioning. The high incidence of false negative temporal artery biopsy reported in some of the papers in the literature may be due either to removing only a small segment of the artery, not examining the entire piece by serial sectioning, or problems in defining giant cell arteritis cases in the first place. Thus, I feel temporal artery biopsy, if done properly and examined correctly, has the highest sensitivity and specificity for detection of giant cell arteritis.

\section{Conclusions}

Our experience shows that none of the parameters mentioned above has $100 \%$ reliability in differentiating arteritic AION from nonarteritic AION. Sometimes there are false negative or even false positive findings. Combined information from all the parameters, however, helps make such a differentiation in almost all cases.

\section{(B) Management of Arteritic AION and Giant Cell Arteritis}

There is universal agreement that arteritic AION should be treated with systemic corticosteroids as an emergency, to prevent any further visual loss. However, there is a good deal of controversy and variation in the literature in the therapeutic regimen advocated in these cases. I shall describe here only what is our practice, which has evolved from my experience of dealing with the disease for the past 20 years.

If there is a reasonable index of suspicion that the patient has giant cell arteritis, with or without visual loss, we start the patient on systemic corticosteroids immediately as a 
prophylaxis, even before doing temporal artery biopsy or getting its results. This is important; it may be unsafe to wait till the biopsy diagnosis is available, since the patient could further lose vision during this interval. If the temporal artery biopsy result and other evidence indicates that there is no giant cell arteritis, the drug can be stopped. The dosage and mode of its administration depends upon the severity of visual loss and systemic manifestations. If a patient presents with no visual symptoms or visual loss, we start with at least $80 \mathrm{mg}$ of oral prednisone daily or even up to $120 \mathrm{mg}$, depending upon the severity of systemic symptoms, ESR and CRP. We do, however, give megadose corticosteroid therapy intravenously to start with on an emergency basis when a patient with symptoms of giant cell arteritis has any one of the following ocular signs or symptoms: (i) visual symptoms (particularly amaurosis fugax), (ii) a complete loss of vision in one eye, or (iii) early evidence of second eye involvement (amaurosis fugax, visual field defect, optic disc oedema, cilioretinal artery occlusion, or sluggish circulation in the central retinal artery). Our megadose therapy consists of giving usually the equivalent of one gram of prednisone slowly by intravenous drip, every $6-8$ hours and 3-4 such doses. This is followed by $120 \mathrm{mg}$ prednisone orally daily. We estimate ESR and CRP daily initially to evaluate the response of the patient to the therapy. ESR and CRP initially show a rapid drop-the response varies a good deal in different patients. We keep the patient on the high doses of prednisone till the marked and rapid initial fall in ESR and CRP changes to a mild downfall (Fig. 8); following this we slowly start to taper down the dosage of prednisone in steps of about $10 \mathrm{mg}$ every $3-4$ days. The response is judged by repeated ESR and CRP, at least once a week till the dosage is about $60 \mathrm{mg}$ daily. No generalisation is possible, because of the wide variation in response by different patients to the treatment from this point on. Some patients respond dramatically, and one can go down with the prednisone dosage faster than in others who respond very slowly. I have seen some patients in whom any reduction of dosage to less than $80 \mathrm{mg}$ results in a rise of ESR and CRP, and one has no option but to stall at that dosage for a much longer time than usual.

Determination of the maintenance dose is a slow, laborious and painstaking job over many months. The guiding principle in determining the dosage is to titrate the dosage of prednisone with the levels of ESR and CRP, the object being to have the lowest levels of ESR and CRP with the lowest level of prednisone. There is no formula or any other way to predict the maintenance dosage required by a particular patient; it is only by trial and error that one can determine this. Once a maintenance dosage is established, the patient is followed much less frequently while on that dose. Our experience of following these patients for up to 15 years has shown that they require maintenance dosage for years-the concept that giant cell arteritis burns itself out after about 9-12 months is not at all true and is based more on clinical impression than on any valid scientific data.

Alternate-day corticosteroid therapy is frequently advocated and even practised for the management of giant cell arteritis. I find that there is a good deal of misunderstanding of this therapy. Fauci ${ }^{39}$ has reviewed the subject admirably. He rightly stated that 'The primary goal in the clinical use of corticosteroids' 'is to balance maximal therapeutic efficacy with a minimum of deleterious side effects.' According to him, alternate-day corticosteroid therapy 'will not interfere with the normal ACTH-cortisol cycle, nor will it expose the tissues to sustained levels of hormone throughout the day'. However, the question arises whether such a regimen can effectively control active inflammatory process such as in giant cell arteritis? Fauci ${ }^{39}$ states that it is quite difficult, if not impossible, to satisfactorily induce a remission with alternate-day corticosteroid therapy in a fulminant or grossly active disease'. All the available evidence seems to indicate that such a regimen has no place in management of active giant cell arteritis. Obviously the next question is whether such a therapy can maintain suppression of inactive giant cell arteritis? Available evidence once again seems to indicate that this is most probably not possible. Moreover, the foremost tactical issue is converting from daily to alternate-day therapy. One cannot do 


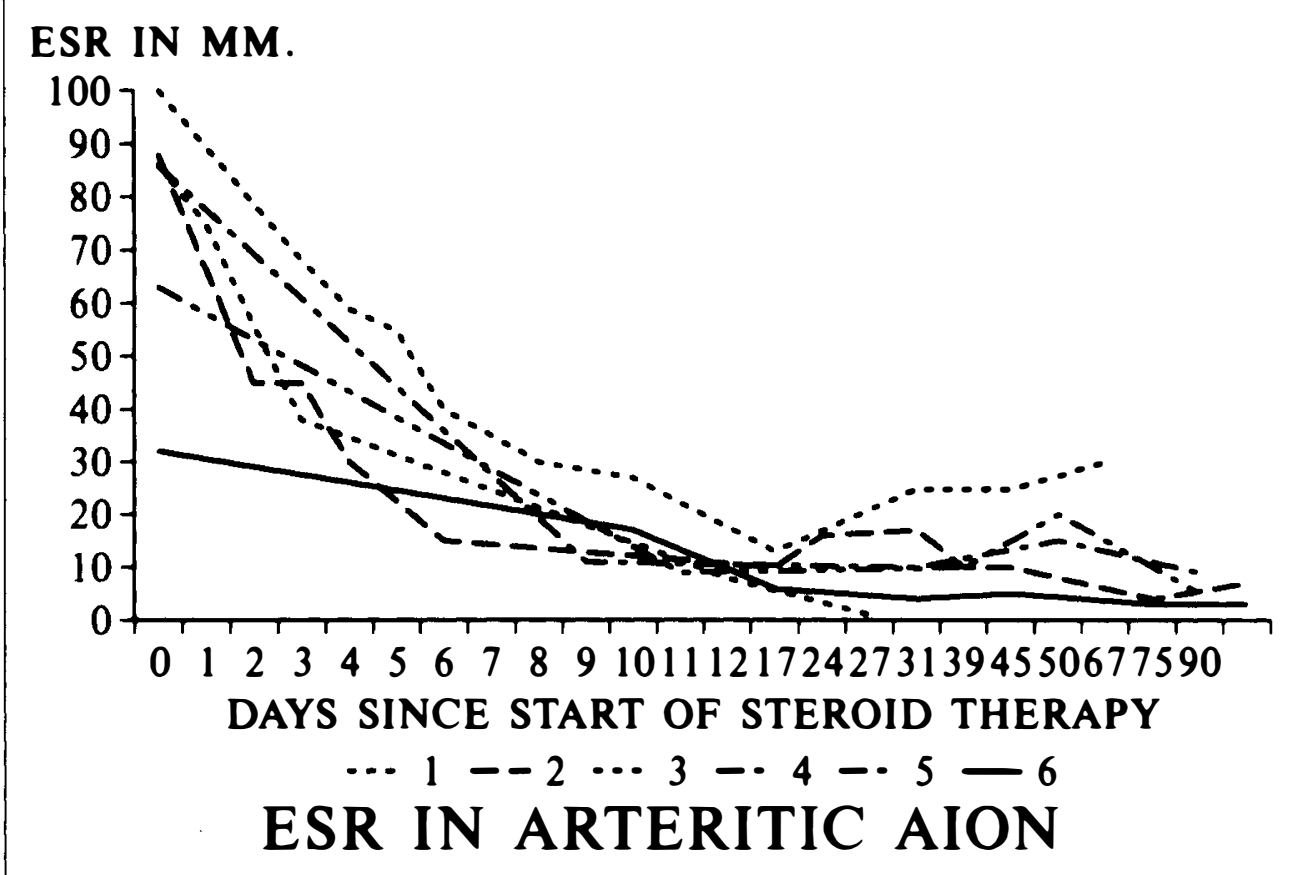

Fig. 8. Graph of (Westergren) erythrocyte sedimentation rates of six patients with arteritic AION, showing their initial responses to high doses of systemic corticosteroid therapy.

it immediately. Fauci ${ }^{39}$ advocates that in such a conversion, one should immediately double the dose on the 'on' days, preferably as a single morning dose, and the dose on the 'off' days is then gradually tapered off. He advises close supervision of the patient during this conversion phase because of the risk of flare-up of inflammatory process. According to him 'the process of conversion may be difficult, at times discouraging and, in some cases, impossible'. I hope this places the alternateday steroid therapy in its true perspective and eliminates all the misunderstandings about it. We have not used alternate-day therapy.

The objectives of corticosteroid therapy: In the management of these patients with giant cell arteritis, we have found it helpful to explain at length at the very beginning the following objects of treatment:

(1) The principal object of the treatment is to prevent blindness. Our experience indicates that during the first week of the therapy one should give a guarded prognosis about any further visual loss because we have found that about $5 \%$ of patients during this period, in spite of the aggressive treatment and even mega dose intravenous corticosteroid therapy, did suffer further loss of vision, even complete blindness, but none after that. We, therefore, feel that one can virtually guarantee that if a person does not suffer any further visual loss for one week after starting treatment with the high doses suggested above, the chance of visual loss after that is practically none. This is proof of the effectiveness of adequate systemic corticosteroid therapy in the prevention of visual loss in giant cell arteritis.

(2) It has been claimed by some authors, from time to time, that aggressive treatment with systemic corticosteroids can restore visual loss in arteritic AION. Our experience does not support this view at all, because, on the whole, we have not seen any worthwhile visual recovery in spite of early, aggressive, megadose steroid therapy. Only a very rare patient has shown some visual improvement. I have frequently found that patients have the impression that aggressive steroid therapy is really meant to reverse their visual loss. To avoid serious disappointment, it is essential to 
stress at the outset that the object of the treatment is not to recover the lost vision but to prevent any further visual loss-if the patient is not aware of this fact, he/she is likely to cooperate poorly with continued treatment and thereby to risk losing further vision.

(3) The most important point to stress is that the treatment is essentially suppressive and not curative, and will be required for years to prevent any further visual loss. This information is vital for regular compliance of the treatment, without any break and as directed. At the same time it is essential to discuss in detail the various complications of prolonged steroid therapy and how to avoid some of them or manage them, so that the patient is not only aware of those but also emotionally and physically prepared for them. It is also vital to involve their local physician in monitoring and management of systemic sideeffects of corticosteroid therapy.

I have found that most ophthalmologists and physicians have either distorted or inadequate information on the management of patients with giant cell arteritis, with or without visual loss. The management of this disease is very taxing both for the patient and for the physician.

Unfortunately, we have no effective and well-established therapy for non-arteritic AION-either for visual recovery or for prophylaxis against the involvement of the second eye, the incidence of which is quite high, particularly in diabetics. ${ }^{19}$

\section{(C) Misconceptions about AION}

A number of serious misconceptions have developed over the years about AION, and these are responsible for misdiagnosis of AION and consequent unnecessary and expensive investigation in those patients. It is important to comment briefly on these misconceptions, which include the following:

\section{AION is exclusively a disease of the elderly}

This is because it is assumed that ischaemic disorders do not occur in young persons. Based on this misconception, in the previous studies on AION reported in the literature, patients younger than 50 or so were excluded from the studies so that AION in those cases was instead diagnosed as optic neuritis. We have found that AION is a disease of all ages and no age is immune from it.

\section{Eyes with AION must be blind or almost blind}

In our studies in non-arteritic AION, $41 \%$ of the eyes had $6 / 12$ or better visual acuity $(26 \%$ had $6 / 6$ ) and $63 \%$ had $6 / 30$ or better (Table). Even in arteritic AION, the visual acuity was $6 / 12$ or better in $26 \%(14 \%$ had $6 / 6)$ and $40 \%$ had $6 / 24$ or better (Table) ${ }^{22}$. Thus, these eyes do not have to be stone blind.

\section{AION always has pale optic disc oedema}

Our experience has shown that during the very early stages, optic disc oedema in nonarteritic AION on ophthalmoscopy may look no different from any other type of optic disc oedema, and the disc may be even hyperaemic. It is only after a couple of weeks or so that the disc starts to show pallor with oedema. Presumably this misconception crept in because the published reports have been from referral centres where the patients were usually not seen early enough. In our series, about half of the eyes with arteritic AION even showed a pattern similar to that seen in non-arteritic AION, and only about half of the eyes with arteritic AION really showed pale oedema of the disc from the very start.

\section{Asymptomatic optic disc oedema is not seen in AION}

My studies ${ }^{18}$ have shown conclusively that asymptomatic optic disc oedema may precede the visual loss in AION. I have collected over 25 such cases over the years.

\section{Neural ischaemia is an 'all or none' phenomenon}

It is well-known that neural ischaemia can vary from sub-clinical to an extreme type. Consequently, the ischaemic damage to the optic nerve head can vary from sub-clinical ${ }^{18}$ to total infarction and the clinical manifestations would differ accordingly.

\section{AION is an early complication of hypertensive arterial disease}

This misconception is based on a report by 
Ellenberger ${ }^{40}$ and his theory was based on a retrospective review of records of only 18 cases of non-arteritic AION! Our prospective, detailed studies on about 525 patients of non-arteritic AION lends no support at all to this view.

\section{Non-arteritic AION patients with systemic hypertension have increased risk of cerebrovascular accidents and myocardial infarction}

This opinion was based on a retrospective review of records of 212 patients with nonarteritic AION. ${ }^{41}$ This has created a certain amount of unnecessary fear in AION patients. From a prospective follow-up of about 525 patients in our Clinic up to 15 years, I have so far detected no support for this view.

I am grateful to my wife Shelagh for her help with the manuscript, to Mrs. Ellen Ballas and Mrs. Georgiane Parkes-Perret for their secretarial help, and to the photography department for the illustrations.

\section{References}

${ }^{1}$ Hayreh SS and Baines JAB: Occlusion of the posterior ciliary artery III. Effects on the optic nerve head. Br J Ophthalmol 1972, 56: 754-64.

${ }^{2}$ Hayreh SS: Anterior ischaemic optic neuropathy I. Terminology and pathogenesis. Br J Ophthalmol 1974, 58: 955-63.

${ }^{3}$ Hayreh SS: Anterior ischemic optic neuropathy. New York. Springer-Verlag, 1975.

${ }^{4}$ Hayreh SS: Pathogenesis of visual field defectsRole of the ciliary circulation. Br J Ophthalmol 1970, 54: 289-311.

${ }^{5}$ Hayreh SS: Structure and blood supply of the optic nerve. In Heilmann K, Richardson KT eds. Glaucoma: Conceptions of a disease. Pathogenesis, diagnosis, therapy, Stuttgart: Thieme 1978: 78-96.

${ }^{6}$ Hayreh SS: Inter-individual variation in blood supply of the optic nerve head. Its importance in various ischemic disorders of the optic nerve head, and glaucoma, low-tension glaucoma and allied disorders. Doc Ophthalmol 1985, 59: 217-46.

${ }^{7}$ Hayreh SS: Blood supply of the anterior optic nerve. In Ritch R, Shields MB, Krupin T eds. The Glaucomas, Vol. I. St Louis: CV Mosby 1989: 133-61.

${ }^{8}$ Hayreh SS: Blood supply of the optic nerve head in health and disease. In Lambrou GN, Greve EL eds. Ocular blood flow in glaucoma. Amsterdam: Kugler \& Ghedini 1989: 3-48.

${ }^{9}$ Hayreh SS: The ophthalmic artery III. Branches. $\mathrm{Br}$ J Ophthalmol 1962, 46: 212-47.

${ }^{10}$ Hayreh SS: Physiological anatomy of the choroidal vascular bed. Int Ophthalmol 1983, 6: 85-93.
${ }^{11}$ Hayreh SS and Baines JAB: Occlusion of the posterior ciliary artery I. Effects on choroidal circulation. Br J Ophthalmol 1972, 56: 719-35.

${ }^{12}$ Hayreh SS and Zahoruk RM: Anterior ischemic optic neuropathy VI. In juvenile diabetics. Ophthalmologica 1981, 182: 13-28.

${ }^{13}$ Hayreh SS, Servais GE, Virdi PS: Fundus lesions in malignant hypertension V. Hypertensive optic neuropathy. Ophthalmology 1986, 93: 74-87.

${ }^{14}$ Hayreh SS: Anterior ischemic optic neuropathy VIII. Clinical features and pathogenesis of posthemorrhagic amaurosis. Ophthalmology 1987, 94, 1488-502.

${ }^{15}$ Hayreh SS: Optic disc edema in raised intracranial pressure VI. Associated visual disturbances and their pathogenesis. Arch Ophthalmol 1977, 95: 1566-79.

${ }^{16}$ Hayreh SS: Anterior ischemic optic neuropathy IV. Occurrence after cataract extraction. Arch Ophthalmol 1980, 98: 1410-16.

${ }^{17}$ Hayreh SS: Anterior ischemic optic neuropathy. Arch Neurol 1981, 38: 675-8.

${ }^{18}$ Hayreh SS: Anterior ischemic optic neuropathy V. Optic disc edema an early sign. Arch Ophthalmol 1981, 99: 1030-40.

${ }^{19}$ Beri M, Klugman MR, Kohler JA, Hayreh SS: Anterior ischemic optic neuropathy VII. Incidence of bilaterality and various influencing factors. Ophthalmology 1987, 94: 1020-8.

${ }^{20}$ Beck RW, Servais GE, Hayreh SS: Anterior ischemic optic neuropathy IX. Cup-to-disc ratio and its role in pathogenesis. Ophthalmology 1987, 94: 1503-8.

${ }^{21}$ Hayreh SS: Ischemic optic neuropathy. Int Ophthalmol 1978, 1: 9-18.

${ }^{22}$ Hayreh SS and Podhajsky P: Visual field defects in anterior ischemic optic neuropathy. Doc Ophthalmol Proc Ser 1979, 19: 53-71.

${ }^{23}$ Hayreh SS: Anterior ischaemic optic neuropathy II. Fundus on ophthalmoscopy and fluorescein angiography. Br J Ophthalmol 1974, 58: 964-80.

${ }^{24}$ Jennings GH: Arteritis of the temporal vessels. Lancet 1938, 1: 424-8.

${ }^{25}$ Paulley JW and Hughes JP: Giant-cell arteritis, or arteritis of the aged. Br Med J 1960, 2: 1562-7.

${ }^{26}$ Hedlund P: Clinical and experimental studies on C-reactive protein (Acute phase protein). Acta Med Scand Suppl 1961, 361: 1-71.

${ }^{27}$ Lawlor GJ and Fischer TJ: Manual of allergy and immunology-diagnosis and therapy. Boston. Little Brown \& Co, 1984: 277.

${ }^{28}$ Eshagian $\mathbf{J}$ and Goeken JA: C-reactive protein in giant cell (cranial, temporal) arteritis. Ophthalmology 1980, 87: 1160-6.

${ }^{29}$ Bosley TM, Savino PJ, Sergott RC, Eagle RC, Sandy R, Gee W: Ocular pneumoplethysmography can help in the diagnosis of giant-cell arteritis. Arch Ophthalmol 1989, 107: 379-81.

${ }^{30}$ Singh S and Dass R: The central artery of the retina I. Origin and course. Br J Ophthalmol 1960, 44: 193-212. 
${ }^{31}$ Birkhead NC, Wagener HP, Shick RM: Treatment of temporal arteritis with adrenal corticosteroids: results in fifty-five cases in which lesion was proved at biopsy. J Am Med Assoc 1957, 163: 821-7.

${ }^{32}$ Cohen DN and Smith TR: Skip areas in temporal arteritis: myth versus fact. Trans Am Acad Ophthalmol Otolaryngol 1974, 78: OP772-83.

${ }^{33}$ Albert DM, Ruchman MC, Keltner JL: Skip areas in temporal arteritis. Arch Ophthalmol 1976, 94: 2072-7.

${ }^{34}$ Klein RG, Campbell RJ, Hunder GG, Carney JA: Skip lesions in temporal arteritis. Mayo Clin Proc 1976, 51: 504-10.

${ }^{35}$ Wells KK, Folberg R, Goeken JA, Kemp JD: Temporal artery biopsies correlation of light microscopy and immunofluorescence microscopy. Ophthalmology 1989, 96: 1058-64.
${ }^{36}$ Blodi FC: The temporal artery biopsy as a diagnostic procedure in ophthalmology. Trans Aust Coll Ophthalmol 1969, 1: 26-33.

${ }^{37}$ Hedges TR III, Gieger GL, Albert DM: The clinical value of negative temporal artery biopsy specimens. Arch Ophthalmol 1983, 101: 1251-4.

${ }^{38}$ Hall S, Lie JT, Kurland LT, Persellin S, O'Brien PC, Hunder GG: The therapeutic impact of temporal artery biopsy. Lancet 1983, 2: 1217-20.

${ }^{39}$ Fauci AS: Alternate-day corticosteroid therapy. Am J Med 1978, 64: 729-31.

${ }^{40}$ Ellenberger C: Ischemic optic neuropathy as a possible early complication of vascular hypertension. Am J Ophthalmol 1979, 88: 1045-51.

${ }^{41}$ Guyer DR, Miller NR, Auer CL, Fine SL: The risk of cerebrovascular and cardiovascular disease in patients with anterior ischemic optic neuropathy. Arch Ophthalmol 1985, 103: 1136-42. 